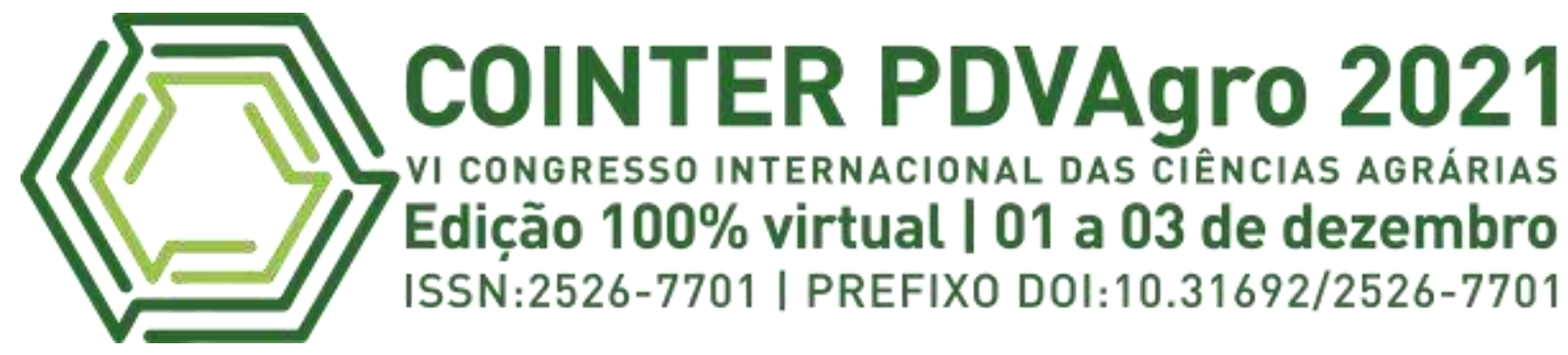

\title{
EXTENSÃO RURAL UNIVERSITÁRIA: PROJETOS VIGENTES E PERSPECTIVAS FUTURAS NA UFRA CAMPUS CAPANEMA-PA
}

\author{
AMPLIACIÓN RURAL UNIVERSITARIA: PROYECTOS ACTUALES Y \\ PERSPECTIVAS FUTURAS DEL CAMPUS UFRA CAPANEMA-PA
}

\section{UNIVERSITY RURAL EXTENSION: CURRENT PROJECTS AND FUTURE PERSPECTIVES IN UFRA CAMPUS CAPANEMA-PA}

\author{
Apresentação: Comunicação Oral \\ Jhonatah Albuquerque Gomes ${ }^{1}$; Luiz Cláudio Moreira Melo Júnior ${ }^{2}$; Ana Karlla Magalhães Nogueira ${ }^{3}$
}

DOI: https://doi.org/10.31692/2526-7701.VICOINTERPDVAgro.0038

\begin{abstract}
RESUMO
As universidades devem nortear suas ações atendendo ao padrão de indissociabilidade entre ensino, pesquisa e extensão. Conforme a Constituição Federal, é dever da Universidade oferecer estas ferramentas de forma igualitária, sem predominância do "produtivismo acadêmico". Logo, a extensão rural pode ser entendida em seu sentido como processo de comunicação, troca de conhecimento e saberes de qualquer natureza, seja este técnico, popular ou cientifico, devendo contribuir para o desenvolvimento social sustentável, em processos endógenos e em uma abordagem multidisciplinar que englobe diversas áreas do conhecimento, sendo assim, este campo é importante para a integração entre sociedade e meio acadêmico. Entretanto, em alguns casos, o interesse pela pesquisa sobrepõe-se a extensão, rompendo como o paradigma multidisciplinar, caracterizando pelo fato da exigência acadêmica de produção técnica-cientifica. Neste sentido, o objetivo deste trabalho foi quantificar os projetos de extensão rural vigentes na Universidade Federal da Amazônia (UFRA), Campus de Capanema, bem como a percepção a nível docente, acerca do processo de desenvolvimento de projetos de extensão no referido Campus. A pesquisa foi desenvolvida na UFRA Campus de Capanema, com a revisão de dados disponíveis em plataformas digitais e aplicação de questionários semiestruturados aplicado junto aos docentes que atuam no curso de Agronomia do Campus. Constatou-se que a instituição conta com 15 projetos de extensão ativos. Foi observado que a principal barreira existente para a execução de projetos de extensão, é a questão do financiamento dos projetos. Atestou-se ainda que, $83 \%$ dos docentes não possuem projetos de extensão rural, entretanto, $83 \%$ almejam futuramente trabalhar na área.
\end{abstract}

Palavras-Chave: Interiorização universitária, tripé da universidade, produtivismo acadêmico

\section{RESUMEN}

Las universidades deben orientar sus acciones teniendo en cuenta el patrón de inseparabilidad entre docencia, investigación y extensión. De acuerdo con la Constitución Federal, es deber de la Universidad ofrecer estas herramientas por igual, sin el predominio del "productivismo académico". Por tanto, la extensión rural puede entenderse en su sentido como un proceso de comunicación, intercambio de saberes y saberes de cualquier índole, ya sea técnico, popular o científico, y debe contribuir al desarrollo social sostenible, en procesos endógenos y en un enfoque multidisciplinario que engloba varias áreas del conocimiento, por lo tanto, este campo es importante para la integración entre la sociedad y la 
academia. Sin embargo, en algunos casos, el interés por la investigación se superpone a la extensión, rompiendo con el paradigma multidisciplinario, caracterizado por el hecho de la exigencia académica de la producción técnico-científica. En este sentido, el objetivo de este trabajo fue cuantificar los proyectos de extensión rural vigentes en la Universidad Federal de la Amazonía (UFRA), Campus de Capanema, así como la percepción a nivel docente sobre el proceso de desarrollo de proyectos de extensión. en ese Campus. La investigación se desarrolló en la UFRA Campus de Capanema, con la revisión de los datos disponibles en plataformas digitales y la aplicación de cuestionarios semiestructurados aplicados a los docentes que laboran en el curso Campus Agronomía. Se encontró que la institución cuenta con 15 proyectos de extensión activos. Se observó que la principal barrera existente para la ejecución de proyectos de extensión es el tema del financiamiento de proyectos. También se constató que el $83 \%$ de los docentes no tiene proyectos de extensión rural, sin embargo, el $83 \%$ apunta a trabajar en el área en el futuro.

Palabras Clave: Interiorización universitaria, trípode universitario, productivismo académico

\begin{abstract}
Universities must guide their actions taking into account the pattern of inseparability between teaching, research and extension. According to the Federal Constitution, it is the University's duty to offer these tools equally, without the predominance of "academic productivism". Therefore, rural extension can be understood in its sense as a process of communication, exchange of knowledge and knowledge of any nature, whether technical, popular or scientific, and should contribute to sustainable social development, in endogenous processes and in a multidisciplinary approach that it encompasses several areas of knowledge, therefore, this field is important for the integration between society and academia. However, in some cases, the interest in research takes precedence over extension, breaking with the multidisciplinary paradigm, characterized by the fact of the academic requirement of technical-scientific production. In this sense, the objective of this work was to quantify the rural extension projects in force at the Federal University of the Amazon (UFRA), Campus de Capanema, as well as the perception at the teaching level about the process of development of extension projects in that Campus. The research was developed at UFRA Campus de Capanema, with the review of data available on digital platforms and application of semi-structured questionnaires applied to teachers who work in the Campus Agronomy course. It was found that the institution has 15 active extension projects. It was observed that the main existing barrier to the execution of extension projects is the issue of project financing. It was also attested that $83 \%$ of teachers do not have rural extension projects, however, $83 \%$ aim to work in the area in the future.
\end{abstract}

Keywords: University interiorization, university tripod, academic productivism

\title{
INTRODUÇÃO
}

As universidades possuem como um de seus métodos educacionais, o "tripé" formado por ensino, pesquisa e extensão. Diante disso, o Art. N 207/1996, da Constituição Federal de 1988 apresenta que as universidades devem obedecer a um padrão de indissociabilidade entre ensino, pesquisa e extensão. Outrossim, cabe as instituições a efetivação de tal fato, não se prendendo somente a ensino e pesquisa; contudo, tendo como obrigatoriedade o uso de sua função social, analisando, debatendo e equacionado as diferentes mazelas existentes além dos "'muros" da universidade, despertando olhar crítico, senso pensante e racionalidade (ARAÚJO et al, 1998).

Assim, a extensão rural pode ser entendida em seu sentido mais amplo, como processo de comunicação, troca de conhecimento e saberes de qualquer natureza, seja este técnico, popular ou cientifico (PEIXOTO, 2008). Segundo o Plano Nacional de Assistência Técnica e 
Extensão Rural (PNATER, 2011) a extensão rural deve contribuir para o desenvolvimento social sustentável, em processos endógenos e em uma abordagem multidisciplinar que englobe diversas áreas do conhecimento, sendo assim, este campo é importante para a integração entre sociedade e meio acadêmico. Entretanto, em alguns casos, o interesse pela pesquisa sobrepõese a extensão, rompendo como o paradigma multidisciplinar, caracterizando pelo fato da exigência acadêmica de produção técnica-cientifica, conhecido como "produtivismo acadêmico"' (YAMAMOTO et al, 2012).

Por conseguinte, Freire (1992) destaca que, a forma de lapidar teoria é pensar na própria prática; afirmando que quanto mais um indivíduo faz reflexões se pondo no lugar do público alvo, vendo a realidade não de forma idealizada, porém, objetiva e desafiadora, mais ele se aproxima da "razão", tendo assim, uma teoria pura, que é verdadeiramente aceitável.

Assim, afirma-se que a extensão universitária é uma práxis indissociável e que sua efetivação deve ocorrer não somente por meio da universidade, porém, também formando parceria com instituições de extensão, como por exemplo, a empresa de Assistência Técnica e Extensão Rural (EMATER), afim de garantir um intercâmbio de conhecimento, rompendo o paradigma de que a universidade, os docentes e os discentes são os únicos detentores de conhecimento.

De acordo com dados do Relatório de autoavaliação institucional (2018) da Universidade Federal Rural da Amazônia (UFRA), Campus de Capanema, ainda são necessários mais recursos para investimento em extensão rural universitária, e ainda são insipientes as políticas que proporcionem mais facilidades para a realização dos projetos de extensão. Por conseguinte, há necessidade de avaliar a usualidade do "tripé" da universidade (Ensino, pesquisa e extensão), justificando a cobrança de verbas para sua real efetivação; haja vista que, a conquista do saber não se dá somente através de teorias, fórmulas acadêmicas e conhecimento cientifico, todavia, através do amago das relações sociais, que são criados a partir da troca de saberes, proporcionados pela extensão rural universitária (BASTO, 1991).

Logo, o objetivo deste estudo é quantificar os projetos de extensão vigentes na Universidade Federal Rural da Amazônia, Campus Capanema, bem como a percepção a nível docente quanto a criação e efetivação de novos trabalhos na área em destaque e saber quais os principais entraves existentes para sua efetivação e quais os cursos de graduação mais participantes nestes projetos.

\section{FUNDAMENTAÇÃO TEÓRICA}


Segundo Santos (2004), existe uma sobreposição do conhecimento cientifico em termo de pesquisa e ensino, contraposto ao modelo extensionistas. Este "modelo" é chamado de “injustiça cognitiva" (OLIVEIRA, 2004). O conhecimento humano quando produzido em meios acadêmicos, tem por papel ser compartilhado com a sociedade (CUNHA, 1991). Diante do pressuposto, é indiscutível o papel do pesquisador extensionista no meio rural, objetivando a troca mutua de saberes e conhecimento; rompendo com paradigmas. Para isso, cabe as universidades a formação de profissionais extensionistas, formados a partir da indissociabilidade da universidade em usar seu tripé (ensino pesquisa e extensão), rompendo o paradigma do ensino reprodutivo, oriundo de modelos positivistas, com objetivo de alcançar o sistema de produção, fundamentado no modelo humanista-dialógico, cuja a instalação é dependente de pesquisa e extensão. (ARAÚJO, 1997).

A extensão rural na universidade se explica pela necessidade de profissionais que venham entender os interesses e desejos da população que vive na zona rural, executando os conhecimentos adquiridos em sala de aula em consonância com os conhecimentos empíricos que está população já possui, servindo então, de fonte realimentadora e irradiadora de novas pesquisas (ARAÚJO, 1995). Logo, diante do pressuposto, a prática da extensão rural, além de necessária, deve ser pensada, afim de sanar e propor formas eficientes de suprir as necessidades do público rural; pensado em uma extensão rural funcional.

Segundo Paulo Freire (1992), a forma de lapidar teoria é pensar na própria prática; afirmando que quanto mais um individuo faz reflexões se pondo no lugar do público alvo, vendo a realidade não de forma idealizada, porém, objetiva e desafiadora, mais ele se aproxima da “'razão", tendo assim, uma teoria pura, que é aceitável. Diante de suas ideias, pode-se afirmar que possivelmente, para uma pesquisa de qualidade, deve se antes se por no lugar do público alvo, indo até onde ele está; por meio da extensão rural.

Assim, afirma-se que a extensão universitária é uma práxis indissociável e que sua efetivação deve ocorrer não somente por meio da universidade, porém, também formando parceria com instituições de extensão, com EMATER, afim de garantir um intercambio de conhecimento, rompendo o paradigma de que a universidade, os docentes e os discentes são os únicos detentores de conhecimento, mas sim, alvos ativos desta relação. Reutilizando Freire (1989), pensar a prática, leva a perfeita teoria.

\section{METODOLOGIA}


O estudo foi realizado na UFRA, Campus Universitário de Capanema, localizado no Município de Capanema, Nordeste do estado Pará, com coordenadas geográficas $1^{\circ} 11^{\prime} 25^{\prime \prime}$ latitude Sul, e 4709'38' longitude Oeste e altitude média local de $25 \mathrm{~m}$ (Figura 01).

Figura 01 - Localização geográfica da UFRA/Capanema-PA.

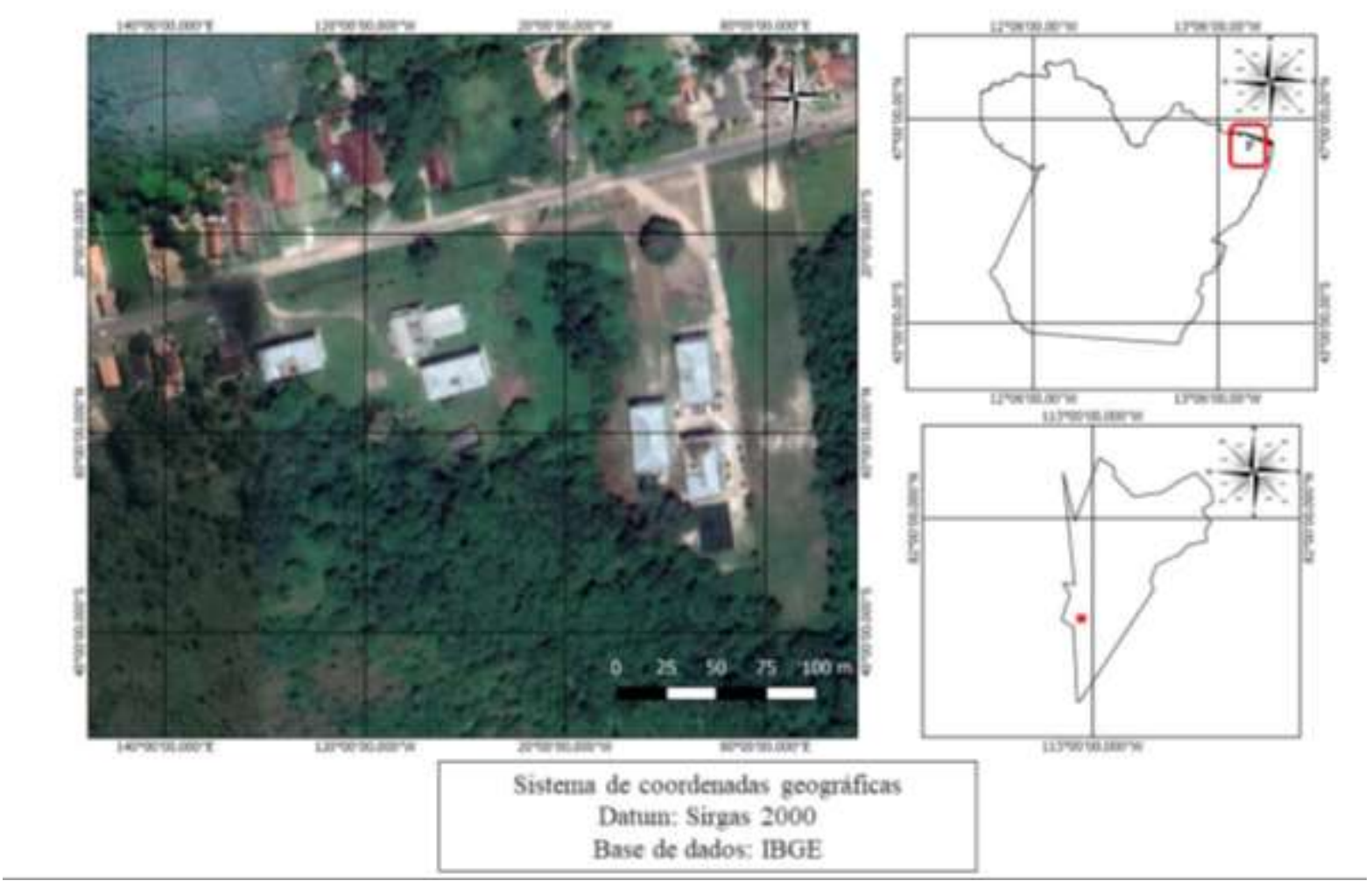

Fonte: Própria (2019)

Os dados quantitativos de projetos vigentes em extensão, foram coletados via plataforma digital das Pró-Reitoria de extensão (PROEX) da UFRA por meio dos documentos oficiais disponibilizados no site institucional. Os dados foram tabulados, seguindo a sua respectiva grande área.

Ademais, o questionário foi aplicado em dois dias, nos turnos matutinos e vespertinos, para 22 dos 37 docentes efetivos do curso de agronomia da UFRA/Capanema, seguindo a metodologia descrita por Carson e Louviere (2011) e Ives e Kendal (2014), que se apresenta com perguntas abertas e fechadas, possibilitando maior percentagem de respostas ao entrevistado. As perguntas foram direcionadas aos docentes do curso de bacharelado em agronomia da UFRA/Capanema e se relacionaram ao cunho de perspectivas, barreiras existentes na área de extensão rural e se há interesse em trabalhos futuros na área. Os resultados foram tabulados no software Excel® para plotagem dos gráficos

\section{RESULTADOS E DISCUSSÃO}


De acordo com os dados coletados, 59\% do quadro de professores do curso de agronomia da UFRA Campus Capanema, não são membros de projetos de extensão rural, em contraponto a $41 \%$ que são participantes. Segundo Jezine (2004), as dificuldades existentes para a efetivação de projeto de extensão universitária, desde logística à disponibilidade do discente, são fatores que causam redução na demanda de docentes dedicados a estes projetos. Isto possivelmente ocorre ainda, em decorrência da necessidade de diversos processos burocráticos para o cadastro de projetos de extensão rural ou mesmo a ausência de afinidade com área.

Ainda foi evidenciado que $33,33 \%$ dos docentes afirmam que, nesta universidade é dado tratamento diferenciado para ensino. Isto se deu possivelmente, pôr no período onde foi realizada esta pesquisa, ainda não havia no Campus de Capanema, programas de pósgraduação; o que exigem maior tempo em sala de aula, com mais teoria e menos prática, com afirma Souza (2015). Para pesquisa, foi observado um quantitativo de 12,5\%, justificado por motivo do baixo incentivo da universidade para pesquisa (RELATÓRIO DE AUTOAVALIAÇÃO INSTITUCIONAL, 2018). Foi observado que apenas 8,33\% dos docentes afirmam que é dado tratamento diferencia para extensão, haja vista que, o surgimento de novas bolsas de pesquisa como o Programa de Iniciação Cientifica em Extensão (PIBEX). Logo, 45,83\% dos entrevistados afirmaram que não há tratamento diferenciado para o tripé da universidade, dados semelhantes podem ser observados no relatório de autoavaliação institucional (2018).

É sabido a importância da pesquisa visto que, esta é a base da descoberta do saber cientifico (OLIVEIRA, 2001). Entretanto, Vasconcelos (1996), apresenta que o tripé da instituição deve funcionar sem falta de nenhuma das vertentes, sendo obrigação da universidade levar ensino, pesquisa e extensão aos discentes, tornando-se opcional a cada docente optar por uma área de interesse. Como uma das maneiras de sanar tais-deficiências deve haver ações articuladas entre a Pró-Reitoria de Extensão, com coordenadorias de curso e grupos de pesquisa, por meio de projetos que disponibilizem bolsas de extensão estudantil, firmando ações de implementação com políticas do Ministério da educação -MEC (SANTANA, NOGUEIRA; 2016).

Além disso, uma das vertentes abordadas pelos docentes quanto as principais barreiras existentes para a execução de projetos de extensão rural, destacam-se em ordem decrescente, financiamento, logística do campus, insuficiência de recursos, ausência de auditório, número de bolsas de extensão, poucas parcerias institucionais, pouco estímulo a grupos de pesquisa e demanda de discente reduzida para trabalhar com extensão rural (Figura 02).

Figura 02 - Principais dificuldades existentes para a execução de um projeto de extensão 


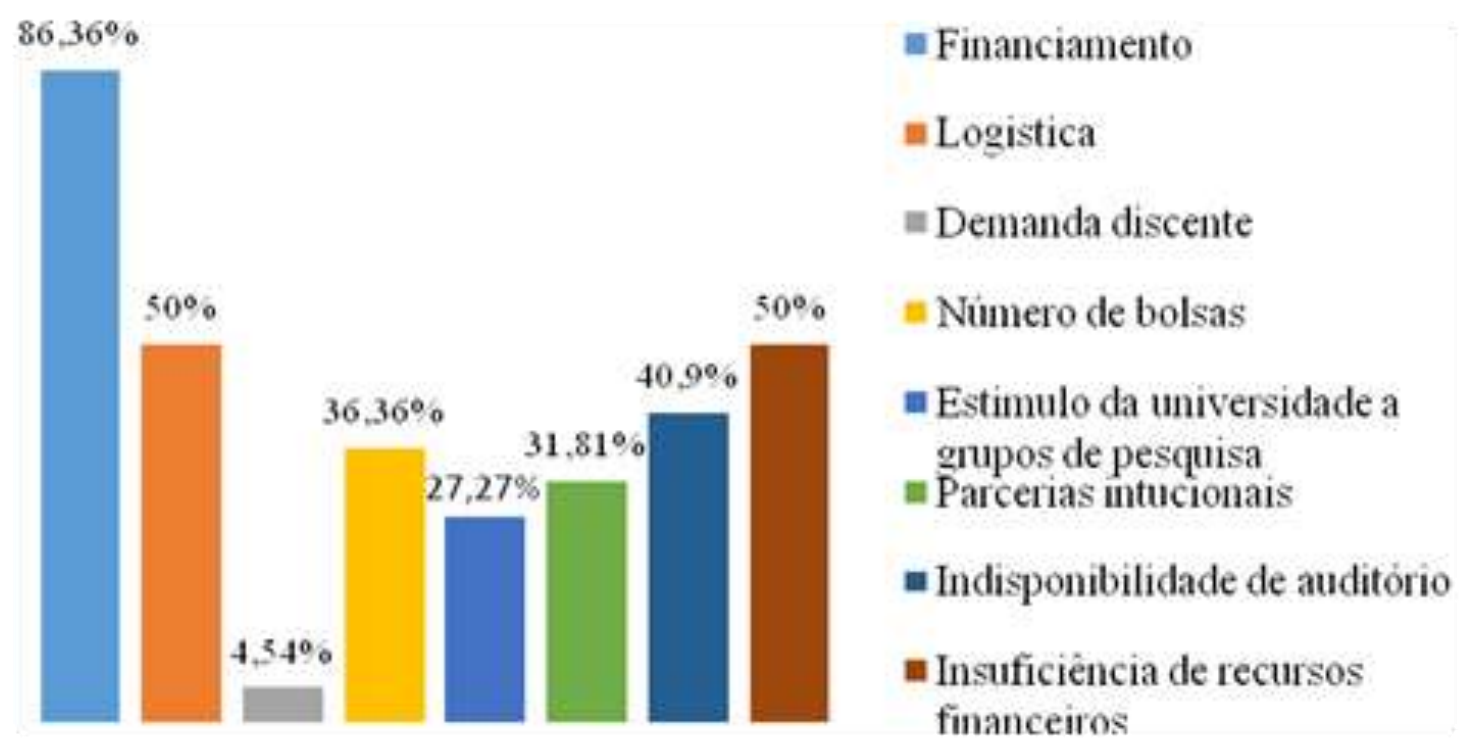

Fonte: Própria (2019).

Estes dados vislumbram a necessidade da UFRA, como instituição de ensino superior, formar e articular estratégias que busquem angariar fundos para a execução de projetos de extensão ou mesmo direcionar de forma igualitária a verba destinada a projetos, para ensino, pesquisa e extensão (SOUZA, 2016); estes processos podem ocorrer desde a filiação a órgãos externos, como EMATER e Empresa Brasileira de Pesquisa Agropecuária (EMBRAPA).

Segundo o Relatório de Autoavaliação Institucional (2018), a Universidade ainda carece de fomento em projetos de extensão, o que complementa os resultados obtidos na pesquisa, revelando que, na percepção dos docentes, as ações de estímulo dado aos discentes com bolsas de pesquisa, extensão e monitoria ainda são reduzidas no Campus Capanema. Outro fator que influencia diretamente na execução de projetos de extensão, é a logística do Campus, inicialmente marcada com a indisponibilidade de transporte até as comunidades ao entorno, bem como o difícil acesso as comunidades rurais. Diante disso, ocorre a inviabilidade processual e contínua de caráter educativo e social da extensão como um todo (MARQUES, 2019).

Assim, a formulação e a implementação das ações para a Extensão Universitária, devem ser subsidiadas por meio das seguintes diretrizes: Interação Dialógica, Interdisciplinaridade e interprofissionalidade, indissociabilidade Ensino-Pesquisa-Extensão, Impacto e transformação (NOGUEIRA, 2000).

A partir destas vertentes, ações de extensão universitária, visando os docentes podem ser mais facilmente adquiridas, visto que, um baixo percentual de professores é participantes de projetos de extensão. No que compete a coordenação de projetos de extensão, possivelmente a redução de participantes é reduzida devido aos processos burocráticos necessários para isso. 
Ademais, nenhum dos entrevistados são coordenador e participante simultaneamente dos projetos de extensão, isto dá possivelmente, como exemplifica Nogueira (2000), pela necessidade dos fatores de mão dupla que compõe a matriz da extensão rural, como interdisciplinalidade e intercomunicação, serem ferramentas que exigem tempo e dedicação, tornando inconciliável ao docente, fazer ensino em salas de aula, pesquisa e extensão ao mesmo tempo, ressaltando que, de acordo com a legislação, o docente pode optar por uma área de interesse. Os resultados ainda demonstram que a maioria dos professores envolvidos em projetos de extensão, são membros participantes, geralmente integrando grupos de estudo (MENDES, 2014).

Do total de professores empenhados em projetos de extensão rural, a área de maior destaque foi a educação. Este fato pode ter ocorrido por motivo da educação circuncidar a maioria das temáticas de pesquisa, principalmente em comunidades rurais, como afirma Leoni (2018). Evidenciou-se, ainda, que os projetos de extensão com temática de meio ambiente são em sua maioria (84\%) ocupados por discentes do curso de bacharelado em engenharia ambiental; fato que possivelmente se deu em decorrência do curso de engenharia ambiental apresentar disciplinas mais específicas da área ambiental que os demais cursos de graduação da UFRA/Capanema. Para as áreas de olericultura e fitotecnia, não foi observado nenhum resultado, podendo ter ocorrido em decorrência do campus dispor de apenas de dois professores com formação na área.

No que tange o empenho discente, $42 \%$ dos entrevistados afirmam que a necessidade de mais bolsa para extensão, ainda são barreiras vigorosas para a execução de projetos de extensão. Os dados ainda mostram que, há interesse por meio do alunado em fazer parte de projetos de extensão, visto que, apenas $12 \%$ dos docentes alegam que há pouco interesse discente em participar de projetos da área. Este resultado é relevante, pois a amostra é baixa quando comparada as demais variáveis analisadas. A participação discente em projetos de extensão, pode ser afirmada com base na Figura 03.

Logo, a UFRA Campus de Capanema oferece ainda, bolsas na área de ensino, na modalidades de residênsia pedagógicas, monitoria e afins, na área de pesquisa, com bolsas de PIBIC (Programa Institucional de Bolsas de Iniciação Científica), PIBIT (Programa Institucional de Bolsas de Iniciação Científica Tecnológica) e em extensão universitária a bolsa de PIBEX (Programa Institucional de bolsas de Extensão Universitária).

Figura 03 - Área de atuação dos projetos de extensão do campus da UFRA/Capanema (2019). 


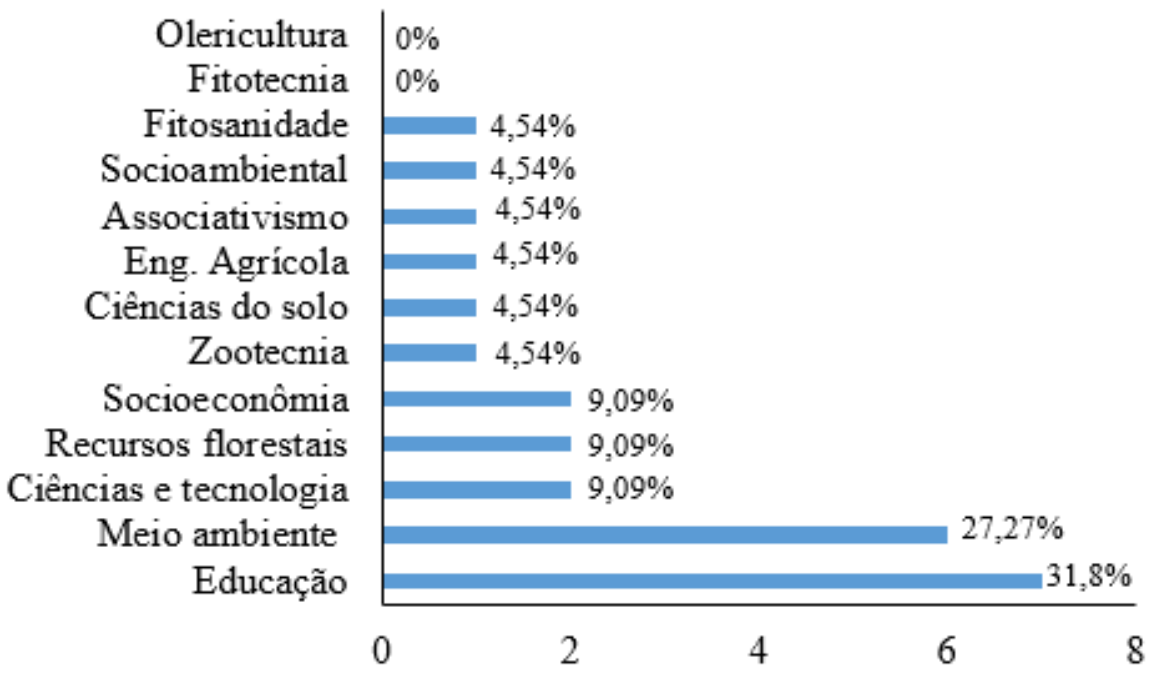

Fonte: Própria (2019).

De acordo com a figura 3, a menor demanda de estudantes envolvidos em projetos de extensão, se deu em cursos noturnos de Administração e ciências contábeis. Fato este que, pode ter ocorrido em virtude de grande parte dos alunos do turno da noite possuírem vínculo empregatício e dedicarem maior parte de seu tempo as atividades extra acadêmicas (RELATÓRIO DE AUTOAVALIAÇÃO INSTITUCIONAL, 2018). Os cursos de Agronomia e engenharia ambiental apresentaram os maiores quantitativos de alunos envolvidos em projetos de extensão (Eng. Ambiental = 19, Agronomia = 17, Licenciatura em biologia = 7, bacharelado em biologia $=6$, contabilidade $=1$, administração $=0$ ), isto pode ter ocorrido em virtude de os cursos supracitados apresentarem maior contato com o campo e com o meio rural se comparado aos demais.

Figura 04 - Participação discente em projetos de extensão no Campus da UFRA/Capanema (2019).

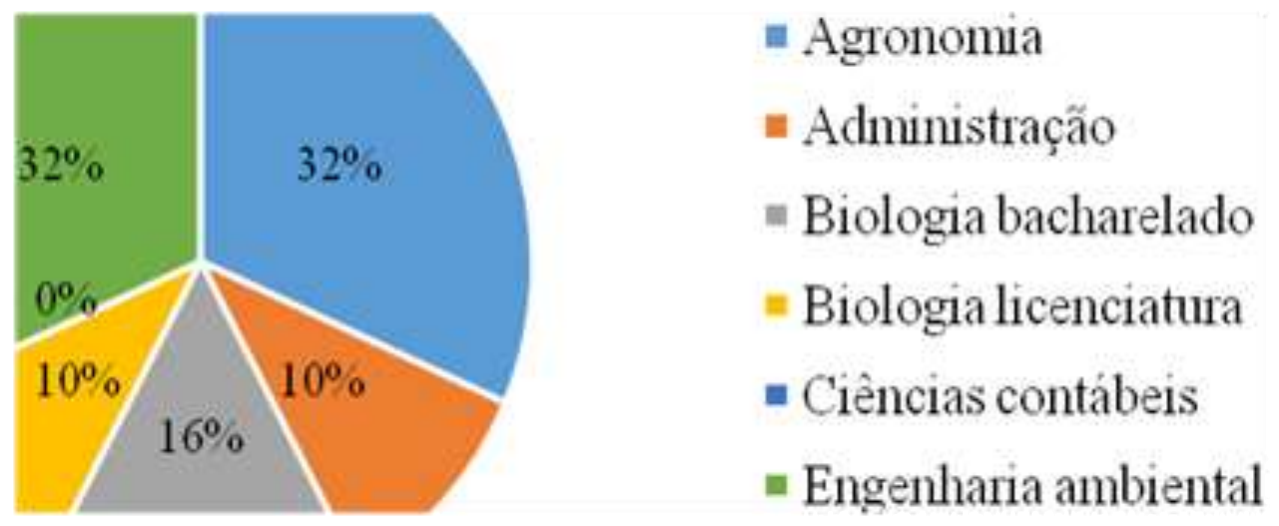

Fonte: Própria (2019).

Os resultados indicam, ainda, que $81 \%$ dos docentes possuem interesse em trabalhar 
com extensão, e 9\% que afirmou não ter interesse na área. De acordo com o Art. N $^{\circ}$ 203/1998, cabe a cada docente trabalhar em sua área de afinidade. Diante dos fatos, pode-se dizer que, os docentes que não almejam futuramente trabalhar com extensão, estejam foram dos padrões, porém, apenas não apresentam desejo de trabalhar na área; cabendo a universidade, criar ações para fortalecer está área, visto que, por lei, a instituição tem a obrigação de oferecer ensino, pesquisa e extensão, uma vez que, a maior porcentagem da grande área dos projetos de extensão circunda a educação.

De acordo com informações obtidas junto a Pró-Reitoria de Extensão, o Campus de Capanema-PA, dispõe de 15 projetos cadastrados e ativos. É possível afirmar que, este quantitativo se dá em decorrência de 53,3\% dos projetos serem cadastrados como grupos de pesquisa, enquadrando-se em extensão rural. Este montante, destaca o Grupo de Estudo Socioambientais da Amazônia - GESA e o projeto Difusão de Saberes e Conhecimentos Rurais e Ambientais da Diversidade Amazônica; ambos possuem contato direto com o público rural, de forma diferenciada em relação aos demais.

Quandro 01 - Projetos de extensão vigentes na UFRA Campus Capanema, cadastrados junto a Pró-Reitoria de Extensão.

\begin{tabular}{|c|}
\hline PROJETOS VIGENTES - UFRA/Capanema \\
\hline $\begin{array}{c}\text { Aproveitamento de resíduos sólidos domésticos como forma de contribuir para redução } \\
\text { de impactos ambientais resultante do resíduo urbano do Município de Capanema. }\end{array}$ \\
\hline Grupo de Estudos Socioambientais na Amazônia - GESA \\
\hline Grupo de Estudos em Manejo Integrado de Pragas - GEMIP \\
\hline Grupo de Estudos em Olericultura na Amazônia - GEOA \\
\hline BIOARTS'S: O Teatro como Estratégia para o Ensino de Biologia \\
\hline $\begin{array}{c}\text { Valorização dos produtos locais como alternativa para geração de emprego e renda do } \\
\text { Estado do Pará, Amazônia, Brasil }\end{array}$ \\
\hline Difusão de Saberes e Conhecimentos Rurais e Ambientais da Diversidade Amazônica \\
\hline Empresa Júnior: Consultoria Ambiental e Energias Renováveis (CONAMBER) \\
\hline Grupo de Ensino e Aprendizagem em Contabilidade e Finanças para o ENADE e \\
EXAME DE SUFICIÊNCIA 2017 - GRECO \\
\hline GEPEA- Grupo de Estudos sobre Processo de Ensino-Aprendizagem \\
\hline Projeto GECEC - Grupo de Estudos em Educação Científica e Ensino de Ciências. \\
\hline Programa de combate à violência: a dignidade da mulher ufraniana \\
\hline Grupo de Estudos em Agricultura Irrigada na Amazônia - GEAIA \\
\hline $\begin{array}{c}\text { Grupo de Estudos de Melhoramento Genético animal da Amazônia - MeGA: Ações } \\
\text { Extensionistas para melhoria da produção animal }\end{array}$ \\
\hline $\begin{array}{c}\text { Do Ensino Médio para o ensino Superior: uma abordagem na escala profissional com } \\
\text { enfoque no curso de agronomia, Capanema - PA. }\end{array}$ \\
\hline
\end{tabular}

Fonte: Própria (2019)

A relação de projetos ativos cadastrados na Proex (Pró-reitoria de Extensão), teve última 
atualização em 27 de agosto de 2019, porém, novos projetos podem ser cadastrado via módulo de extensão, no Sistema Integrado em Gestão de Atividades Acadêmicas - SIGAA. O projeto intitulado de "Aproveitamento de resíduos sólidos domésticos como forma de contribuir para redução de impactos ambientais resultante do resíduo urbano do Município de Capanema', foi cadastrado em meados do ano de 2015, com público estimado em 50 pessoas. O Grupo de Estudos Socioambientais na Amazônia - GESA, foi cadastrado inicialmente em 2016, porém, em 2021 teve sua segunda fase homologada cadastrada via módulo de extensão, com público estimado em 100 pessoas.

Segundo o coordenador do projeto (2021), este se fundamenta em abordagens teóricas e metodológicas transversais, mobilizando conceitos e categorias como interação sistêmica, diálogo de saberes, diversidade socioambiental, saberes locais, pesquisa-ação, educação ambiental e do campo, políticas públicas, sustentabilidade, participação e desenvolvimento local, propondo o constantes diálogo de saberes entre a vida acadêmica e a vida camponesa, promovendo a interação acadêmica entre estudantes, técnicos e professores da UFRA e estimulando debates com a comunidade local do município de Capanema e seu entorno, envolvendo atores sociais comunitários para a consolidação do Campus da UFRA em Capanema como referência de excelência no campo da integração entre extensão, pesquisa e ensino universitários no nordeste do estado do Pará. O GEMIP - Grupo de Estudos em Manejo Integrado de Pragas, iniciou-se em 2016, com público estimado entre docentes, discentes e externos em 60 pessoas.

O Grupo de Estudos em Olericultura na Amazônia - GEOA, possui público estimado em 10 pessoas, entre docentes e discentes. Segundo a coordenadora do projeto (2021), o grupo busca instrumentalizar estudantes dos cursos de graduação da UFRA para entendimento das diferentes situações que permeiam a realidade da agricultura familiar, tendo como base a produção de hortaliças, contribuindo para a melhoria das condições de realização das ações da Universidade junto aos produtores de Olerícolas da região do Nordeste Paraense, no raio de influência da UFRA/Capanema, propondo trabalhos constantes de assistência técnica junto aos produtores, para disseminação das diferentes técnicas vivenciadas pelos discentes da UFRA, estabelecendo uma troca de experiências entre discentes e professores.

O projeto “BIOARTS'S: O Teatro como Estratégia para o Ensino de Biologia", cadastrado na PROEX em 2017, com público estimado em 100 pessoas, em busca o ensino do teatro em escolas da rede pública, com alternativa do ensino lúdico da biologia. O projeto Valorização dos produtos locais como alternativa para geração de emprego e renda do Estado do Pará, Amazônia, Brasil, cadastrado em 2017, estima participação de 30 pessoas, objetivando 
a difusão dos produtos oriundos na Amazônia, para a comunidade externa.

O projeto intitulado de Difusão de Saberes e Conhecimentos Rurais e Ambientais da Diversidade Amazônica, cadastrado em 2017, com público alvo de 10 pessoas, visa a produção de conhecimento técnico- científico a respeito das práticas de produção, conservação e formas de utilização dos recursos naturais em espaços urbanos e rurais da Amazônia, refletem uma grande oportunidade de compartilhar saberes e conhecimento no contexto da universidade, das comunidades e outros interessados.

A Empresa Júnior: Consultoria Ambiental e Energias Renováveis - CONAMBER, cadastrada e 2017, com público estimado em 100 pessoas, é vinculada ao Curso de Engenharia Ambiental e Energias Renováveis, cujo objetivo consiste em propiciar ao aluno a interação da teoria e prática no mercado ainda no contexto universitário e não apenas na condição de formado. O Grupo de Ensino e Aprendizagem em Contabilidade e Finanças para o ENADE e EXAME DE SUFICIÊNCIA 2017 - GRECO, cadastrado em 2018, é direcionado a discentes do curso de administração e ciências contábeis, a fim de propiciar aos estudantes conhecimento sobre ENADE e Exame de suficiência.

O GEPEA- Grupo de Estudos sobre Processo de Ensino-Aprendizagem, castrado em 2017, com público estimado de 100 pessoas e público real alcançado de 60 pessoas, de acordo com a coordenadora (2021), busca disponibilizar espaços de formação crítica continuada de docentes, por meio da troca de experiências de professores atuantes na rede pública de ensino juntamente com os discentes interessados nos diferentes aspectos do processo de ensinoaprendizagem. O grupo está voltado para discutir as questões relacionadas ao processo de ensino-aprendizagem, de maneira a proporcionar uma formação crítica continuada tanto para professores atuantes na rede pública de ensino como para futuros professores.

O Projeto GECEC - Grupo de Estudos em Educação Científica e Ensino de Ciências, cadastrado inicialmente em 2018, teve nova submissão de proposta em 2021; o projeto tem público estimado em 2 pessoas; a coordenadora do projeto (2021), justifica sua criação pela necessidade de construir, junto com os estudantes dos cursos de licenciatura em Biologia da UFRA, conhecimento, no tocante ao viés da educação em ensino de Ciências, destacando a necessidade da alfabetização científica dos discentes.

O projeto intitulado de "Programa de combate à violência: à dignidade da mulher ufraniana", cadastrado em 2018, possui público estimado de 100 pessoas, buscando propriciar segurança às discentes da UFRA contra crimes diversos dentro da instituição. O Grupo de Estudos em Agricultura Irrigada na Amazônia - GEAIA, cadastrado em 2019, uni discentes dos cursos de Engenharia Ambiental e Agronomia, a fim de propor práticas de irrigação efetivas 
na Amazônia.

O Grupo de Estudos de Melhoramento Genético animal da Amazônia - MeGA: Ações Extensionistas para melhoria da produção animal, cadastrado em 2019, de acordo com a coordenadora (2021), visa melhorar a execução da extensão, um dos tripés da Universidade, levando o conhecimento produzido dentro da instituição para a sociedade e vice-versa. Estas ações afetarão positivamente os discentes estimulando a prática dos conhecimentos adquiridos, o aprendizado em campo e a disseminação das informações produzidas. Além disso, o grupo de estudos fortalecerá ainda mais a integração da Universidade com a sociedade, trabalhando a nível local e regional para atender as demandas da região a nível local e, assim, contribuir para o desenvolvimento da região amazônica.

O projeto 'Do Ensino Médio para o ensino Superior: uma abordagem na escala profissional com enfoque no curso de agronomia, Capanema - PA', castrado em 2019, com público estimado de 100 pessoas, destina discentes do curso de agronomia as escolas públicas no município de Capanema, a ministrarem palestras sobre o referido curso, desmistificando visões estereotipadas e levando aos alunos o primeiro contato com o saber científico.

Portanto, os projetos de extensão da UFRA Campus de Capanema, tiveram início legal em meados de 2016, e mantêm-se até os dias atuais, gerando troca de saberes e conhecimento com a comunidade externa.

\section{CONCLUSÕES}

Conclui-se que entre os principais entraves, o financiamento se mostrou como a principal barreira para a efetivação de projetos de extensão. Pode-se perceber que ainda há escassez de projetos de extensão nesta universidade. A UFRA possui 15 projetos de extensão ativos até 2019 e, não é dado tratamento diferenciado para ensino, pesquisa e extensão. Ainda, $88 \%$ dos docentes possuem perspectivas futuras em trabalhar com extensão rural. O primeiro projeto de extensão da UFRA Campus de Capanema ativo, foi cadastrado em 2016.

\section{REFERÊNCIAS}

Araújo, Manoel M.; Wizniewsky, José G.; Tsukahara, Roberto T.; Araújo, Leandro L. A Prática Da Indissociabilidade Do Ensino-Pesquisa-Extensão Na Universidade. Revista brasileira de agrociência, Pelotas, p. 1-6, 1 set. 1998.

Araújo, Manoel Mendieta. Dia Especial - Atividadeintegrada De Ensino, Pesquisa E Extensão Rural - Dcsa/Faem/Ufpel - 30/03/95 (Folder) Pelotas/Ufpel. 1995. 4 P.

\section{Bastos, João de Augusto De S.A. A Educação Técnicoprofissional:Fundamentos,}


Perspectivas Eprospectivas. $1^{\text {a }}$ ED., BRASÍLIA: SENETE, 1991. 120 P. BIASI, CARLOS A. F. METODOLOGIA. Curitiba, EMATER.

CORREA, L. R. Análise do perfil socioeconômico dos discentes dos cursos de Administração eCiências Contábeis da Universidade Federal Rural da Amazônia (UFRA), Campus Capanema:2014 a 2018. 2019. 51 f. Trabalho de Conclusão de Curso (Bacharelado em Administração) -Universidade Federal Rural da Amazônia, Capanema, PA., 2019

CUNHA, MARIA ISABEL DA. Do sonho a realidade - projeto pedagógico da ufpel - na construção de uma nova universidade. Editora Universitária -UFPEL, 1991. 39

FREIRE, PAULO. E SHOR., IRA. Medo e ousadia - o cotidiano do professor. $4^{\text {a }}$ ED. RIO DE JANEIRO. Paz eTerra, 1992. 224 p.

PEIXOTO, M..Marcos Legais Dos Serviços Precursores De Ater No Brasil. IN: Congresso Brasileiro de Assistência Técnica e Extensão Rural Conbater, 2008, Londrina. Congresso Brasileiro De Assistência Técnica E Extensão Rural Conbater

PINTO, JOÃO BOSCO metodologia e prática social.

IN:AGRICULTURAALTERNATIVA.Passo Fundo, CETAP.1988. 7p.

FAZZI, R.G.; NOGUEIRA, A. K. M. ; Martins, L.C. P.; MELO JR., L.C.M; COSTA, T.V. P; SILVA, M.E.S.; MELO, J.R.T.; LIMA, A.S.; SILVA, A.,K., N.; TANALA, A., H. A; RAMOS, A. Relatório de autoavaliação institucional: 2018-2021.Capanema: UFRA, 2019. $67 \mathrm{p}$.

MARQUES, Joil Moreira et al. Detecção de anticorpos anti-Toxoplasma gondii em animais de uma comunidade rural do Mato Grosso do Sul, Brasil. Semina: Ciências Agrárias, p. 889-897, 2009.

OLIVEIRA ANDRADE, Bruno; SANTOS, Maria Salett Tauk. Extensão rural e cibercultura: o facebook como ferramenta de promoção da política nacional de assistência técnica e extensão rural. Extensão Rural, v. 22, n. 3, p. 29-47, 2015.

SANTANA, A. C.; NOGUEIRA, A. K. M. Relatório de autoavaliação institucional: 20132014.Belém: UFRA, 2015. 67p.

SANTANA, A. C.; NOGUEIRA, A. K. M. Relatório de autoavaliação institucional: 2015. Belém:UFRA, 2016. 49 p.

SANTOS, Ailton Dias dos Santos. Mudanças institucionais e organizacionais na assistência técnica e extensão rural (ATER): um estudo de política comparada nos estados do Tocantins, Acre e Rondônia. 2004. 